\title{
Ressonâncias da Alegoria Benjaminiana no Pensamento de Boaventura: a realidade não pode ser reduzida ao que existe
}

\section{Dilson Miklos}

Jornalista, professor do curso de Pedagogia do Instituto Superior de Educação do Rio de Janeiro (ISERJ), doutorando do Programa de Pós-Graduação em Educação da Universidade Federal do Estado do Rio de Janeiro (UniRio)), pesquisador do GPPF/UniRio (Grupo de Pesquisa: Práticas Educativas e Formação de Professores) vinculado à Rede de Formação Docente: Narrativas e Experiências (Rede Formad) e mestre em Ciência da Arte (PPGCA-UFF).

Livre do meu ofício, gosto de cantar o Brasil caboclo, tão longe de tudo aqui. Canto esse Brasil, como quem faz uma prece, para que ele resista à pesada mão do progresso vazio que insiste em dizimá-lo, e para que suas "modas de viola," com seu encantamento, ainda por muito tempo, façam vibrar nossos coraçôes. ${ }^{1}$

\section{Resumo}

O artigo apresenta as ressonâncias do pensamento do filósofo alemão Walter Benjamin na obra do sociólogo português Boaventura de Souza Santos, tal aproximação ressalta uma filiação que lança luzes sobre os escombros soterrados e as vozes silenciadas pelo projeto moderno pautado na ideia de progresso. Libertar a História do seu universalismo e propor uma nova abordagem para o tempo e o espaço está no cerne da construção textual.

Palavras-chave: História, Experiência, Epistemologia, Progresso.

\section{Abstract}

The article presents the resonances of thought of the German philosopher Walter Benjamin in the work of the Portuguese sociologist Boaventura de Souza Santos, which highlights a membership that sheds light on buried debris and voices silenced by the modern project based on the idea of progress. Free the history of its universalism and propose a new approach to time and space is at the heart of textual construction.

Keywords: History, Experience, Epistemology, Progress

\section{Resumen}

El artículo presenta las resonancias del pensamiento del filósofo alemán Walter Benjamin en la obra del sociólogo portugués Boaventura de Souza Santos, lo que pone de relieve una membresía que arroja luz sobre los desechos y las voces silenciadas por el proyecto moderno basado en la idea de progreso enterrado. Libertad para la historia de su universalismo y proponer un nuevo enfoque para el tiempo y el espacio está en el corazón de la construcción textual.

Palabras clave: Historia, Experiencia, Epistemología, Progreso.

1Fragmento do caderno de trabalho de Maria Bethânia e parte integrante da exposição "Maria de Todos Nós", no Paço Imperial/ RJ, que comemora os 50 anos de carreira da cantora no ano de 2015. 
A obra de Walter Benjamin tem sido objeto das mais variadas apropriações e leituras. A intensidade e a coerência do seu pensamento mostram-se atemporais. Existe uma riqueza teórica que não cessa de revelar camadas de significação que se entrecruzam com várias correntes do pensamento moderno e que ecoa além do seu tempo. É exatamente nessa fissura, na ressonância desses ecos, que aproximo o pensador berlinense do sociólogo português Boaventura de Sousa Santos, propondo pensar, através e com eles, uma racionalidade mais cosmopolita que dê conta da diversidade epistemológica do mundo. A construção do artigo não apresenta um percurso metódico, linear, mas flânerie. Percorrendo o labirinto de Benjamin e Boaventura, vamos montando um mosaico possível, um diálogo pautado na convergência de olhares e de apropriações em torno da busca de sentidos que ainda possa valer para pensar a história, o tempo, o mundo, o homem.

Escovar a história a contrapelo (BENJAMIN, 1994). A proposição apresentada por Walter Benjamin nas Teses sobre o Conceito de História ${ }^{2}$, publicadas após sua morte, em 1940, significa a recusa em acreditar na ilusão do progresso, a recusa em acreditar na ideia de que a história tem sentido e direção únicos e conhecidos. É em nome do materialismo histórico que Benjamin contesta as doutrinas do progresso ilimitado e contínuo da social-democracia alemã e do comunismo stalinista. A crítica do progresso é um tema que atravessa o conjunto da obra de Benjamin, desde os seus escritos de 1914 até os últimos textos no final da década de 1930, imprimindo sua desconfiança tanto em seus ensaios teológicos quanto em seus artigos culturais ou políticos. A única exceção, assinala Michel Lowy (1990), são alguns textos dos anos 1933-35, principalmente o ensaio sobre A Obra de Arte na Era de sua Reprodutibilidade Técnica. Benjamin reconhece que o conceito de progresso pode ter tido uma função crítica em sua origem, mas, no século XIX, quando a burguesia conquista posições de poder, essa função desaparece. Não nega que os conhecimentos e as atitudes humanas "progrediram" - nas Teses essa questão é apontada de forma explícita-, o que recusa, tanto no livro Passagens (BENJAMIN, 2006) quanto nos outros escritos de seus últimos anos, é o mito de um progresso que resulta necessariamente das descobertas técnicas, do desenvolvimento das forças produtivas e da dominação crescente sobre a natureza. Ele chama atenção para a utilização bélica das novas técnicas e para o fato de que as máquinas, presumivelmente aliviadoras do fardo do trabalho, nada mais fazem que potencializar a exploração dos oprimidos. Benjamin vaticina: "O conceito de progresso deve ser fundamentado na ideia de catástrofe" (2006, p.515 [N 9a 1]).

$\mathrm{O}$ conceito de progresso está indissociavelmente ligado à concepção de tempo que foi forjada na modernidade e que, como assinala Krishan Kumar (1997), tem seu nascedouro na Idade Média Cristã. É pontualmente com o cristianismo que surge uma nova projeção do tempo e da história, que rompe com a concepção naturalista do mundo antigo, segundo a qual o tempo era apreendido na mudança cíclica das estações, na alternância entre dia e noite ou nos ciclos reprodutivos de nascimento, morte e novo nascimento. Na perspectiva do mundo antigo e pagão, o tempo é cíclico, regular e repetitivo.

O cristianismo introduziu significado e finalidade ao tempo, estabelecendo uma importância única, irrepetível e incomparável a um único evento: a vinda de Cristo. O tempo, a partir desse momento, estava dividido de forma irrevogável entre o tempo "antes" e "depois de Cristo". Santo Agostinho em Confissöes (2001) esclarece que é 
através da recordação do passado e da expectativa dos eventos futuros que cada um de nós percebe o que é o tempo. Ao privilegiar a história humana e a sua dimensão futura, o cristianismo interpreta-a do ponto de vista de seu fim ou consumação final. A história é compreendida então a partir de uma noção de tempo linear, e a ligação entre o passado, o presente e o futuro não é simplesmente cronológica, mas teleológica. O passado alcança significado de modo retrospectivo, isto é, o modo pelo qual formula suas contribuições ao futuro. A história desenvolve-se, como escreve Agostinho, à sombra do futuro. De fato, o cristianismo conta uma história orientada para o futuro, onde o presente é saturado com o objetivo de criar uma atmosfera de expectativa e tensão. $\mathrm{O}$ passado é apenas uma cena introdutória para o tempo presente, cuja flecha está apontada para a promessa do tempo futuro.

Boaventura de Souza Santos (2010) propõe uma racionalidade mais ampla e cosmopolita que a racionalidade moderna ocidental, uma racionalidade que descortine a diversidade epistemológica do mundo e posicione outra temporalidade. A razão ocidental é definida pelo sociólogo como uma razão indolente, responsável pelo desperdício da experiência social que está aprisionada em um modelo único de pensamento. A sociologia das ausências, a sociologia das emergências e o trabalho de tradução compreendem as veredas que fundam a razão cosmopolita. Os pontos de partida são três: a compreensão do mundo excede em muito a compreensão ocidental do mundo; a consciência do mundo e a forma como cria e legitima o poder social está interligada com as concepções de tempo e espaço; a concepção ocidental de racionalidade tem como característica por um lado, contrair o presente e, por outro, expandir o futuro.

"A contraç̧ão do presente, ocasionada por uma peculiar concep̧̧ão de totalidade, consiste em transformar o presente num instante fugidio, entrincheirado entre o passado e o futuro. Do mesmo modo, a concep̧ça linear do tempo e a uniformização da história permitiram expandir o futuro indefinidamente" (SANTOS, 2010, p. 95).

É nesse trânsito de conceitos inovadores que Boaventura, a fim de expandir o presente, propõe uma sociologia das ausências e para contrair o futuro, uma sociologia das emergências. A diversidade de experiências sociais não pode ser explicada por uma teoria geral, é por isso que o trabalho de tradução, de acordo com o sociólogo, é importante, pois viabiliza o processo que cria uma inteligibilidade mútua entre experiências possíveis e disponíveis sem destruir a sua identidade. "Não é possível hoje uma epistemologia geral, não é possível hoje uma teoria geral. A diversidade do mundo é inesgotável, não há teoria geral que possa organizar toda essa realidade" (SANTOS, 2007, p.39).

Benjamin e Boaventura fazem parte de uma constelação de pensadores que lançam luzes sobre os escombros soterrados e as vozes silenciadas. É um esforço que busca revirar esses escombros, capturar a centelha fulgurante do fragmento, libertar a história do seu universalismo e propor uma nova abordagem para o tempo e o espaço. Tanto o rabino marxista ${ }^{3}$ quanto o sociólogo português pensam a história como uma tarefa salvadora, messiânica em relação ao passado e não ao futuro, concebem uma nova teoria da história que permita pensar a emancipação social a partir do pretérito. 
Benjamin, por exemplo, desfere uma crítica contundente à filosofia da história mais influente de sua época - o historicismo - que idealiza escrever a história universal, onde o tempo histórico é semelhante a um espaço homogêneo e vazio, cria, como alternativa teórica, um conceito de tempo - "tempo do agora" (Jetztzeit) - em que o presente não é a mera transição que liga o passado ao futuro. O presente é um tempo saturado de "agoras". Nesta perspectiva, a história não é compreendida como acabada, encerrada em um definitivo "era uma vez". O historiador materialista benjaminiano arranca o seu objeto do continuum do tempo para construí-lo a serviço da própria atualidade, e é na quebra do tempo homogêneo que faz emergir a diferença. O futuro não é a apenas a projeção do tempo na linha evolutiva da história, mas seu desvio em direção ao passado, para que este possa ser alforriado de sua permanente repetição como sofrimento e opressão.

Na Tese XIX, a partir do pequeno quadro de Paul Klee, Benjamin constrói a sua alegoria definitiva da história:

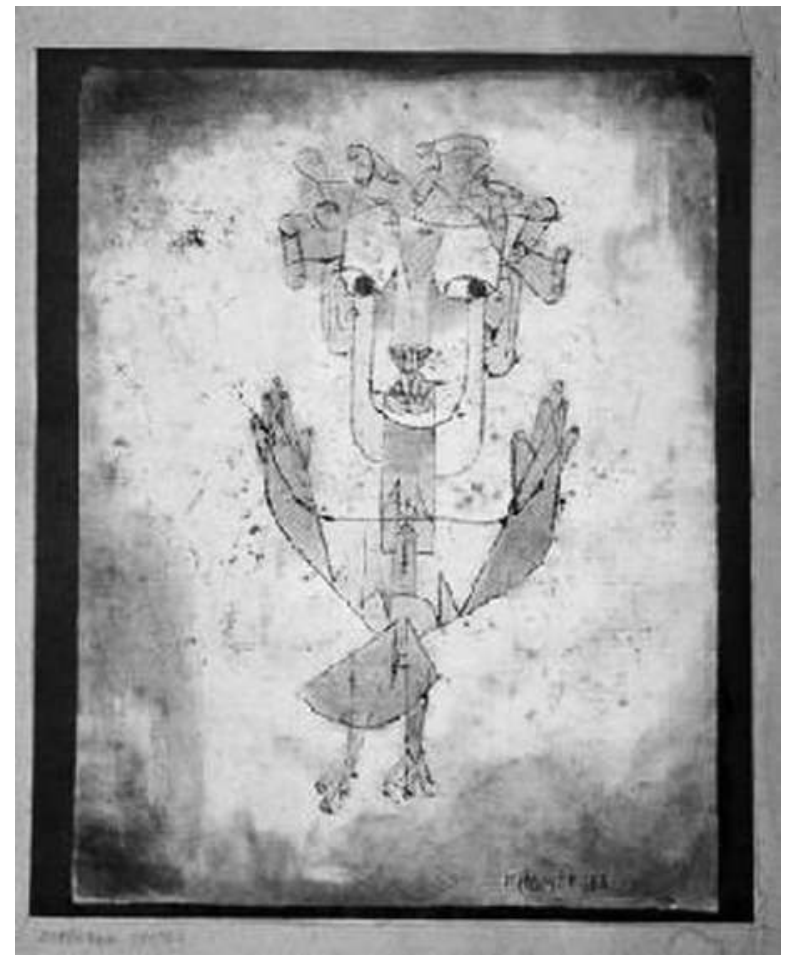

Há um quadro de Klee (ao lado) que se chama Angelus Novus. Representa um anjo que parece querer afastar-se de algo que ele encara fixamente. Seus olhos estão escancarados, sua boca dilatada, suas asas abertas. O anjo da história deve ter esse aspecto. Seu rosto está dirigido para o passado. Onde nós vemos uma cadeia de acontecimentos, ele vê uma catástrofe única, que acumula incansavelmente ruina sobre ruina e as dispersa a nossos pés. Ele gostaria de deter-se para acordar os mortos e juntar fragmentos. Mas uma tempestade sopra do paraíso e prende-se em suas asas com tanta força que ele não pode mais fechä-las. Essa tempestade o impele irresistivelmente para o futuro, ao qual ele vira as costas, enquanto o amontoado de ruinas cresce até o céu. Essa tempestade é o que chamamos de progresso (1994, p.226).

Boaventura se apropria da imagem de Klee e das palavras de Benjamin para refletir o processo histórico dos trabalhadores e dos povos do Sul para quem tão pouco 
interessa o futuro enquanto progresso, uma vez que foi no seu bojo que se perpetuou a dominação e o seu silenciamento.

"O anjo da bistória contempla, impotente, a acumulação de ruinas e de sofrimento a seus pés. Gostaria de ficar, de criar raízes nas catástrofes para, a partir dela, acordar os mortos e reunir os vencidos, mas sua vontade foi expropriada pela força que o obriga a optar pelo futuro para o qual está de costas [...] A capacidade de redenção do passado reside nesta possibilidade de emergir inesperadamente num momento de perigo, como fonte de inconformismo" (SANTOS, 2010, p.53-54).

As alegorias benjaminianas inspiram Boaventura no seu deslocamento teórico, que as arrasta para o tempo contemporâneo a fim de dar sentido a outras vias epistemológicas e libertárias. "O inconformismo dos vivos não existe sem o inconformismo dos mortos” (SANTOS, 2010, p.54), escreve, citando o filósofo berlinense, para destacar que é crucial reposicionar o anjo da história, reinventar o passado restituindo-lhe a capacidade de explosão e redenção, já que é um relato e nunca um recurso, uma força capaz de brotar no momento de perigo em socorro dos vencidos. Boaventura constata que neste início de século há uma oportunidade para romper com essa tradição porque se instalou uma atmosfera de crise pela qual passa atualmente a ideia de progresso.

Nos últimos dois séculos, duas visões do progresso foram introduzidas: a primeira salientou a dimensão evolutiva, e a segunda valorizou as rupturas e a revolução. $\mathrm{O}$ conceito "revolução" foi criado por astrônomos para descrever o curso regular dos corpos celestes e ainda está vinculado a concepção de tempo cíclico que permeou a Antiguidade. No entanto, o termo adquire um novo matiz semântico no século XVIII - corte e inauguração. Neste sentido, a Revolução Francesa de 1789 foi a primeira revolução moderna e uma das principais expressões da nova consciência, anunciando o objetivo do período moderno: a obtenção de liberdade sob a égide da razão. Os tempos modernos tornaram-se o ponto decisivo da civilização ocidental.

Se a Revolução Francesa deu à modernidade sua forma e consciência, a Revolução Industrial Inglesa, no final do século XVIII, modelou sua matéria. Industrialismo não é apenas tecnologia em grande escala, crescimento econômico ou ciência aplicada, identifica-se com a modernidade no momento em que aciona, no conjunto das relações, um sistema permanente de crise e renovação. A determinação que encaminha o desenvolvimento histórico não está no passado nem na eternidade, não está no tempo que é, mas no tempo que ainda não é, ou seja, no tempo futuro. A História é concebida através de uma perspectiva finalística, pautada principalmente nos procedimentos produtivos, cujas etapas, ao se desdobrarem, aspiram à realização final. As revoluções estão inseridas na Era Moderna e, nessa medida, compartilham a concepção de tempo linear.

É exatamente contra a concepção linear do progresso - ideia cara à filosofia das

luzes - que o messianismo benjaminiano e o posicionamento ético e político de Boaventura é dirigido. Em verdade, os pensadores lançam a sua crítica à crença confortável em um progresso contínuo, infinito e automático, fundado apenas na acumulação quantitativa.

"Nunca houve um monumento da cultura que não fosse também um monumento da barbárie," escreve Benjamin na sua VII Tese (1994, p.225). A história, aclamada com a aura da tradição, é aquela que esteve de costas para a verdade dos explorados 
e oprimidos, subtraindo-lhes a capacidade de esperança por um futuro de justiça e felicidade. $\mathrm{O}$ desafio de Benjamin é construir um conceito de história que corresponda à verdade daqueles a quem a tradição da dominação e do ritmo contínuo da história fez calar. A concepção de história das Teses é contrária a qualquer linearidade evolutiva, não há uma ideia de ordem, de um telos. A história como construção é, então, inacabada, descontínua e sujeita a novas origens, e a tarefa do historiador materialista é tirar do esquecimento a história dos vencidos e impelir-se numa dupla libertação: a dos vencidos de ontem e os de hoje. O passado comporta outros futuros além deste que realmente ocorreu.

É no interior dessa reflexão benjaminiana que podemos abrigar as constelações conceituais que Boaventura apresenta para explorar e questionar a razão indolente ${ }^{4}$, que é a expressão do conhecimento hegemônico, tanto filosófico como científico, produzido no Ocidente nos últimos duzentos anos: a razão metonímica e a razão proléptica. A consolidação do Estado liberal na Europa e na América do Norte, as revoluções industriais e o desenvolvimento capitalista, o colonialismo e o imperialismo constituíram o contexto sócio-político no qual a razão indolente se desenvolveu. "Da minha perspectiva, para haver mudanças profundas na estruturação dos conhecimentos é necessário começar por mudar a razão que preside tanto aos conhecimentos como à estruturação deles. Em suma, é preciso desafiar a razão indolente" (SANTOS, 2010, p.97).

A razão metonímica não aceita que a compreensão do mundo é muito mais que a compreensão ocidental do mundo, cristaliza a ideia de totalidade sob a forma da ordem, perpetrando a violência e a destruição como um modus operandi absolutamente natural e reforça, neste compasso de silenciamento, as dicotomias que engendram as articulações e relações de poder hegemônicas. A ampliação do mundo e a dilatação do presente se corporificam no conceito que Boaventura designa por sociologia das ausências, cujo objetivo é transformar objetos impossíveis em possíveis, tornar as ausências em presenças.

"A contracção do presente esconde, assim, a maior parte da riqueza inesgotável das experiências sociais do mundo. Benjamin identificou o problema mas não as suas causas. A pobreza da experiência não é a expressão de uma carência, mas antes a expressão de uma arrogância, a arrogância de não se querer ver e muito menos valorizar a experiência que nos cerca, apenas porque está fora da razão com que a podemos identificar e valorizar"(SANTOS, 2010, p.101).

A experiência (Erfahrung), de forma inequívoca, é um importante conceito na obra de Benjamin que atravessa o conjunto de sua produção ensaística e adquire ângulo e tratamento diferenciados na sua trajetória intelectual - a ela, se associa de forma oposta o conceito de vivência (Erlebnis). A experiência está relacionada ao inconsciente, à tradição, à memória, individual e coletiva; a vivência aponta para uma existência privada, fechada na solidão, circunscrita ao choque e a percepção consciente. Nas sociedades modernas, o esvaziamento da experiência está relacionado a uma valoração da vivência que, aos olhos do filósofo berlinense, é um modo empobrecido do homem experimentar o seu habitar no mundo, não apenas no ambiente onde são

$4 \mathrm{O}$ domínio da razão indolente apresenta-se sob quatro formas: razão impotente (determinismo, realismo), razão arrogante (livre arbítrio, construtivismo), razão metonímica (reducionismo, dualismo) e razão proléptica (evolucionismo, progresso), deter-nos-emos, nesse artigo, sobretudo, à exploração argumentativa das duas últimas formas. 
estabelecidas as relações de trabalho capitalistas, mas igualmente no mundo da arte, da educação e do lazer. A experiência é um lento processo de sedimentação de várias experiências que, mesmo afastadas temporalmente, convergem, ressignificam e se fazem presentes a todo instante. Ao contrário, a vivência é uma série de presentes puros e não mais relacionados na linha do tempo.

Há ainda, no constructo da razão metonímica, a produção de não-existência ${ }^{5}$ que ocorre quando uma expressão é desqualificada, tornada invisível, ininteligível ou, como mesmo destaca Boaventura, descartável de modo irreversível. "O que une as diferentes lógicas de produção de não existência é serem todas elas manifestações da mesma monocultura racional" (SANTOS, 2010, p.102). A sociologia das ausências visa libertar as experiências produzidas como ausentes do contexto de relações que forçaram o seu apagamento e a sua invisibilidade, torná-las presentes, portanto, é legitimar o seu percurso como alternativa que não cabe na totalidade e no tempo linear, é validar a sua credibilidade como fonte argumentativa e via de disputa política frente às experiências hegemônicas. $\mathrm{Na}$ desconstrução da narrativa hegemônica, Boaventura substitui monoculturas por ecologias, ${ }^{6}$ estas são capazes de revelar a diversidade e a multiplicidade das práticas sociais e os diferentes tempos e temporalidades que as culturas geram no interior do seu sistema simbólico. Comum às cinco ecologias é a ideia de que a realidade não pode ser reduzida ao que existe.

A face da indolência quando concebe o futuro a partir da monocultura do tempo linear é a razão proléptica que dilatou de forma colossal o futuro. "Porque a história tem o sentido e a direcção que lhe são conferidos pelo progresso, e o progresso não tem limites, o futuro é infinito. Mas porque o futuro está projectado numa direcção irreversível ele é, como bem identifica Benjamin, um tempo homogéneo e vazio" (SANTOS, 2010, p.115). Enquanto a crítica da razão metonímica objetiva dilatar o presente através da sociologia das ausências, a crítica da razão proléptica materializa a contração do futuro por meio da sociologia das emergências que substitui o vazio do futuro segundo a lógica do tempo linear por um futuro de possibilidades plurais e concretas. "A possibilidade é o movimento do mundo" (2010, p.117), escreve Boaventura que completa:

"A sociologia das emergências consiste em proceder a uma ampliação simbólica dos saberes, práticas e agentes de modo a identificar neles as tendências de futuro (o Ainda-Não) sobre os quais é possivel actuar para maximizar a probabilidade de esperança em relação à probabilidade da frustração" (2010, p.118)

Enquanto a sociologia das ausências amplia o campo das experiências sociais já disponíveis, a sociologia das emergências estende o domínio das experiências sociais possíveis. As duas sociologias estão intrinsecamente vinculadas, visto que quanto mais experiências estiverem disponíveis mais experiências são possíveis no futuro.

E fechando a tríade que potencializa e abre novas possibilidades para instauração de outras vozes epistemológicas, Boaventura apresenta o trabalho de tradução que é complementar à ação das duas sociologias e visa criar inteligibilidade, coerência

5 Boaventura distingue cinco lógicas de produção de não existência: a primeira lógica deriva da monocultura do saber e do rigor do saber; a segunda lógica assenta na monocultura do tempo linear, a terceira lógica é a da classificação social que se constrói na monocultura da naturalização das diferenças; a quarta, é a lógica da escala dominante; finalmente, a quinta lógica é a produtivista que afirma a monocultura dos critérios de produtividade capitalista. 6 São cinco ecologias, a saber: ecologia de saberes; ecologia de temporalidades; ecologia de reconhecimentos; ecologia de trans-escalas; ecologia de produtividades. 


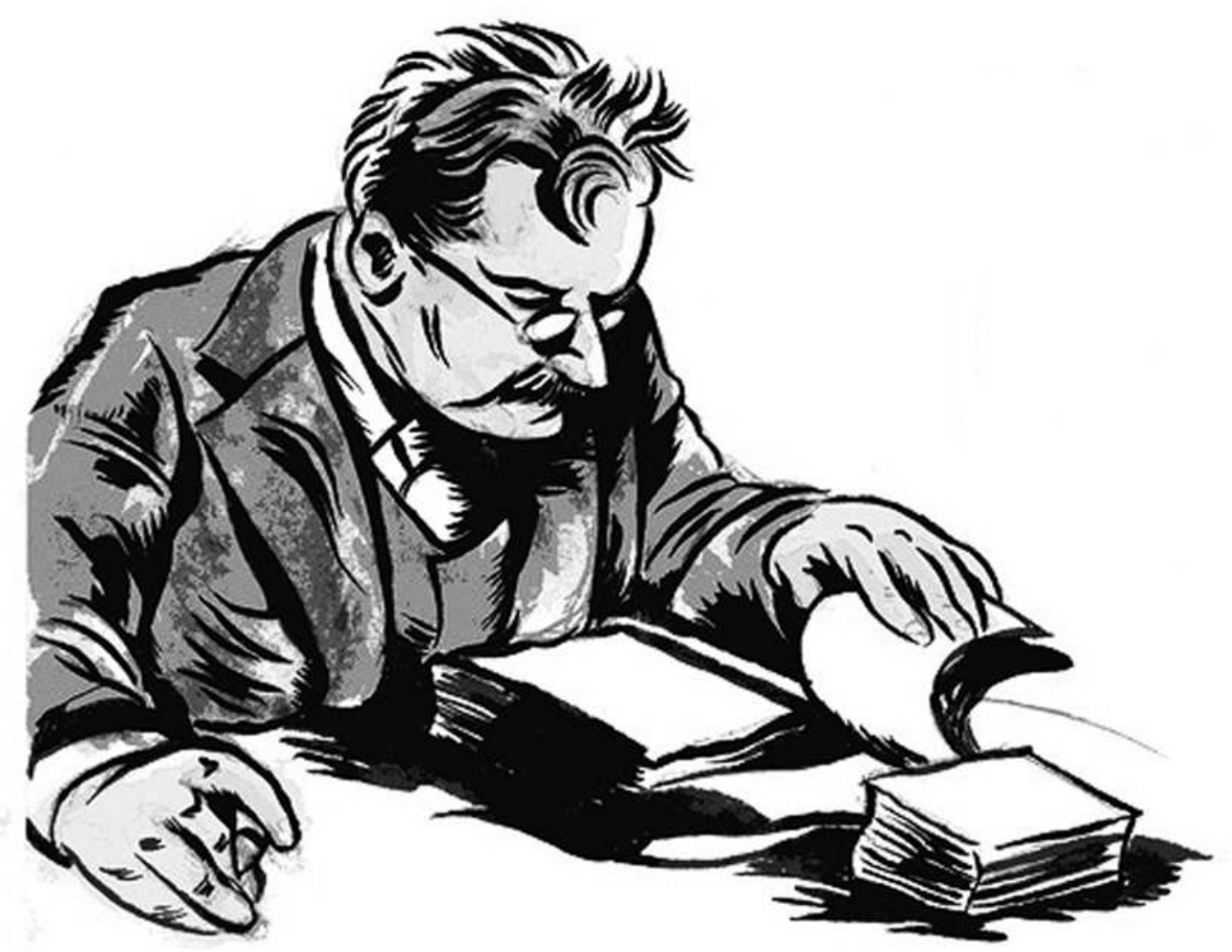

Walter Benjamin. Fonte: http://blogdogutemberg.blogspot.com. br/2010/09/70-anos-sem-walter-benjamin-mas-com-o_22.html.

e articulação dos saberes e práticas sociais em sua natureza múltipla e diversa. A razão cosmopolita, portanto, se concretiza na ação complementar desses três vetores conceituais e defende, como princípio categórico, que não é possível existir justiça social global sem justiça cognitiva global. "O objectivo da tradução entre saberes é criar justiça cognitiva a partir da imaginação epistemológica. $\mathrm{O}$ objectivo da tradução entre práticas e seus agentes é criar condições para uma justiça global a partir da imaginação democrática” (SANTOS, 2010, p.115). O esforço de Boaventura é criar uma alternativa teórica que autorize vir à tona outras narrações porque a história, tal como se configura na atual cartografia, é a canonização do ponto de vista do projeto moderno, uma espécie de "beatificação" dos vencedores, restando aos vencidos o caos, a catástrofe e a ruptura.

$\mathrm{Na}$ teoria da história de Benjamin encontramos em seu centro o conceito de alegoria. A revalorização da alegoria é a chave da estética benjaminiana. $\mathrm{O}$ ensaísta alemão orienta seus estudos, especialmente sobre o drama barroco, mostrando a importância essencial da alegoria na visão barroca do mundo. Em seu escrito capital A Origem do Drama Barroco Alemão (1923 -1925), Benjamin escreve que o objeto alegórico é a representação de outros e até dos vários outros, mas não do todo. Não há, na alegoria benjaminiana, uma representação do universal, pois a alegoria não é a representação da totalidade. A alegoria é fragmento e como tal é pluralista e não monista. Sua maneira de reportar-se ao todo consiste em aludir sem cessar ao outro. Benjamin circunscreve a visão alegórica em uma perspectiva própria:

"Nisso consiste o cerne da visão alegórica: a exposição barroca, mundana, da bistória como história mundial do sofrimento, significativa apenas nos episódios do declínio. Quanto maior a 
significação, tanto maior a sujeição à morte, porque é a morte que grava mais profundamente a tortuosa linha de demarcação entre a physis e a significação. Mas se a natureza desde sempre esteve sujeita a morte, desde sempre ela foi alegórica" (1984, p.188).

Benjamin e Boaventura encarnam o alegorista, execram a história universal que se revela como o eterno retorno do mesmo em uma temporalidade vazia. É uma fantasmagoria dos vencedores. A pobreza da experiência a qual se refere Benjamin, em vários de seus ensaios, não é apenas privada, mas de toda a humanidade. Há a consciência de fazer explodir o continuum da história através da experiência como a concebe o filósofo berlinense e por meio da sociologia das ausências, da sociologia das emergências e da tradução que apontam para percursos promovedores das emancipações epistemológicas. Em Benjamin e Boaventura gravita a ideia de um despertar para uma nova barbárie que talvez possa inaugurar um novo começo onde o bárbaro contente-se com pouco e construa com pouco. É uma barbárie que impõe uma vigilância ética que alimenta a esperança. Os "homens implacáveis"(1994, p.116), citados por Benjamin no ensaio Experiência e Pobreza, de 1933, são esses novos bárbaros. Homens que não foram imobilizados com o peso de sua época. Homens imantados com a atmosfera mítica e comprometidos com a criação.

\section{Referências bibliográficas:}

AGOSTINHO, Santo. Confissões. Tradução de Santos Pina. Petrópolis: Vozes, 2001 BENJAMIN, Walter. A origem do drama barroco alemão. Trad. S. P. Rouanet. São Paulo: Editora Brasiliense, 1984.

. Obras Escolhidas. Trad. S.P. Rouanet. São Paulo: Brasiliense, 1994, v.1. . Passagens. Sao Paulo: Editora UFMG, 2006.

SANTOS, Boaventura de Souza. Renovar a Teoria Crítica e Reinventar a Emancipação Social. São Paulo: Boitempo, 2007.

, Boaventura de Souza. A Gramática do Tempo:para uma nova cultura politica. São Paulo: Cortez, 2010.

D’ANGELO, Martha. Arte, política e educação em Walter Benjamin. São Paulo: Edições Loyola, 2006.

EAGLETON, Terry. A Ideologia da Estética. Rio de Janeiro: Editora Jorge Zahar, 1993. KUMAR, Krishan. Da Sociedade Pós-Industrial à Pós-Moderna. Rio de Janeiro: Jorge Zahar Editor, 1997.

LOWY, Michel. Romantismo e Messianismo: ensaios sobre Lukács e Benjamin. São Paulo: Perspectiva, 1990.

2005. .Walter Benjamin: aviso de incêndio: uma leitura da teses. São Paulo: Boitempo,

MURICY, Kátia. Alegorias da dialética: imagem e pensamento em Walter Benjamin. Rio de Janeiro: Relume Dumara, 1998.

Artigo recebido em dezembro de 2015 e aprovado para publicação em janeiro de 2016. 
CIÊNCIA $\&$ LUTA de CLASSES DIGITAL 